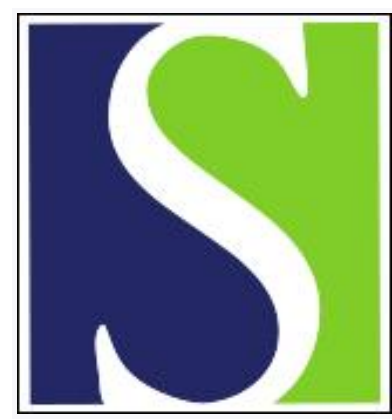

Scand J Work Environ Health 2013;39(1):37-45

https://doi.org/10.5271/sjweh.3301

Published online: 26 Apr 2012, Issue date: Jan 2013

Health-related effects of early part-time sick leave due to musculoskeletal disorders: a randomized controlled trial

by Shiri R, Kausto J, Martimo K-P, Kaila-Kangas L, Takala E-P, Viikari-Juntura E

Affiliation: Finnish Institute of Occupational Health, Topeliuksenkatu 41 a A, FIN-00250 Helsinki, Finland. rahman.shiri@ttl.fi

Refers to the following texts of the Journal: 1996;22(4):251-259

2008;34(4):239-249 2008;34(6):430-437 2010;36(1):25-33

2012;38(2):134-143 2012;38(2):89-91

The following articles refer to this text: 2016;42(4):261-272;

2023;49(1):23-32

Key terms: back; EuroQol; health-related effect; lower extremity; MSD; musculoskeletal disorder; neck; pain; part-time sick leave; quality of life; randomized controlled trial; sick leave; upper extremity

This article in PubMed: www.ncbi.nlm.nih.gov/pubmed/22538838 


\title{
Health-related effects of early part-time sick leave due to musculoskeletal disorders: a randomized controlled trial
}

\author{
by Rahman Shiri, PhD, ${ }^{1,2}$ Johanna Kausto, MSc, ${ }^{1,2}$ Kari-Pekka Martimo, PhD, ${ }^{1,2}$ Leena Kaila-Kangas, \\ PhD, ${ }^{1,2}$ Esa-Pekka Takala, PhD, ${ }^{1,2}$ Eira Viikari-Juntura PhD ${ }^{1}$
}

\begin{abstract}
Shiri R, Kausto J, Martimo K-P, Kaila-Kangas L, Takala E-P, Viikari-Juntura E. Health-related effects of early parttime sick leave due to musculoskeletal disorders: a randomized controlled trial. Scand J Work Environ Health. 2013;39(1):37-45. doi:10.5271/sjweh.3301
\end{abstract}

Objective Previously we reported that early part-time sick leave enhances return to work (RTW) among employees with musculoskeletal disorders (MSD). This paper assesses the health-related effects of this intervention.

Methods Patients aged 18-60 years who were unable to perform their regular work due to MSD were randomized to part- or full-time sick leave groups. In the former, workload was reduced by halving working time. Using validated questionnaires, we assessed pain intensity and interference with work and sleep, region-specific disability due to MSD, self-rated general health, health-related quality of life (measured via EuroQol), productivity loss, depression, and sleep disturbance at baseline, 1, 3, 8, 12, and 52 weeks. We analyzed the repeated measures data (171-356 observations) with the generalized estimating equation approach.

Results The intervention (part-time sick leave) and control (full-time sick leave) groups did not differ with regard to pain intensity, pain interference with work and sleep, region-specific disability, productivity loss, depression, or sleep disturbance. The intervention group reported better self-rated general health (adjusted $\mathrm{P}=0.07$ ) and health-related quality of life (adjusted $\mathrm{P}=0.02$ ) than the control group. In subgroup analyses, the intervention was more effective among the patients whose current problem began occurring $<6$ weeks before baseline and those with $\leq 30 \%$ productivity loss at baseline.

Conclusions Our findings showed that part-time sick leave did not exacerbate pain-related symptoms and functional disability, but improved self-rated general health and health-related quality of life in the early stage of work disability due to MSD.

Key terms back; EuroQol; lower extremity; neck; pain; quality of life; upper extremity.

Musculoskeletal disorders (MSD) are common among working populations and affect general health and quality of life $(1,2)$. Evidence increasingly supports the positive effects of staying active instead of bed rest in the treatment of MSD and associated disability $(3,4)$.

Work is a determinant of good health. Good workplace conditions may have a positive impact on workers' health, especially in common public health problems (5). Long-term sick leave is known to be associated with increased risk of disability pension $(6,7)$. Work participation in most cases has positive effects on health (5). Part-time sick leave avoids the negative effects of full-time sick leave and offers the possibility to remain at work. In part-time sick leave, reduced working time decreases exposure to physical and psychosocial workrelated risk factors. Also flexibility in working patterns may have positive effects on health and wellbeing (8).

Recent register-based studies have reported the effects of partial sick leave among patients on long-term sick leave. A Danish study (9) found a positive effect of a graded return to work (RTW) program on the probability of returning to regular work. A Finnish study (10) showed initially increased recurrence of sick leave but - on a longer prospective - decreased risk of permanent disability after part-time sick leave.

We have previously (11) shown that early part-time

1 Disability Prevention Centre, Finnish Institute of Occupational Health, Helsinki, Finland.

2 Work-related Diseases, Health and Work Ability, Finnish Institute of Occupational Health, Helsinki, Finland.

Correspondence to: Rahman Shiri, Finnish Institute of Occupational Health, Topeliuksenkatu 41 a A, FIN-00250 Helsinki, Finland. [E-mail: rahman.shiri@ttl.fi] 
sick leave leads to earlier RTW and lower rates of subsequent sickness absence compared to full-time sick leave. It is unknown how early RTW affects symptoms, functional disability, self-rated health and quality of life in comparison with full-time sick leave (12). The aim of the current study was to assess the secondary healthrelated outcomes, such as pain intensity and interference with work and sleep and functional disability. In addition, we were interested in self-rated general health, health-related quality of life, depression, sleep disturbance, and productivity loss.

\section{Methods}

The study was carried out in Finland during a period when part-time sick leave was introduced as a sickness benefit. In Finland, employees receive full pay during full-time sickness absence, normally up to two months. During this time, the employer alone pays full salary for ten days (employer period). After this period, the employer receives compensation (up to $70 \%$ of the earned income) from the Social Insurance Institution. Partial sickness allowance was introduced in 2007 for employees aged 16-67 years who are entitled to full sickness allowance, but assessed as being capable of performing $40-60 \%$ of their duties $(10,12)$. In part-time sick leave, however, partial RTW should not compromise health or recovery process.

Up to 2010 and during the present study, partial sickness allowance could be used only after uninterrupted full-time sick leave for almost three months. From 2010 onwards, the part-time RTW scheme provides a partial sickness benefit alongside a partial salary after the employer period. Since early part-time sick leave was not included in the Finnish sickness benefit scheme at the time of the study, specially allocated research funds were used to partially compensate the employers for part-time sick leave exceeding the employer period.

\section{Participants}

Six enterprises participated in this randomized controlled trial (11). Employees who sought medical advice because of musculoskeletal pain were eligible if their symptoms and related disability were severe enough to justify full-time sick leave but allowed working reduced work hours without risk of symptom deterioration.

Inclusion criteria were: (i) employees aged 18-60 years; (ii) permanent or long-term contract of $\geq 30$ working hours per week; (iii) no sick leave due to musculoskeletal problem for $>2$ weeks during the preceding month and not $>30$ days during the preceding 3 months; (iv) no plans for surgical treatment requiring $>1$ week of sickness absence; (v) and no plans for other longer absence (longer than annual paid vacation) during 12 months after enrolment.

Exclusion criteria were: (i) acute infections; (ii) symptoms due to a major accidental injury; (iii) suspected occupational injury or disease; (iv) active inflammatory arthritis; (v) malignant tumor diagnosed or treated during the preceding year; (vi) coexisting severe mental disorder; (vii) pregnancy; and (viii) very severe pain intensity or pain interference with sleep ( $>7$ on a $0-10$ scale). However, 9 patients were included in the study despite the fact that their pain intensity at baseline was $>7$ ( 6 in the control group and 3 in the intervention group).

The Coordinating Ethics Committee at Helsinki University Hospital approved the study.

\section{Intervention}

Patients were randomly allocated to part- or full-time sick leave groups. An occupational health physician recruited them to the study. In four of the six participating enterprises, the physician providing service for the company carried out this recruitment, while the other two enterprises referred eligible patients to the Finnish Institute of Occupational Health.

During the initial visit, the occupational health physician informed the patient about the study and its aims. Since arrangements for part-time sick leave (and part-time work) require negotiations at the workplace, permission to contact the worker's supervisor was requested. Thereafter informed consent was signed including permission to collect information on sick leave days with diagnoses from the registers of the occupational health service three months preceding and one year after recruitment. Permission was also requested to use employment data from the employers' registers one year after recruitment. The occupational physician carried out a symptom interview and performed a physical examination according to a standardized protocol (13, 14). Within a few days, the participants completed an internet-based baseline questionnaire on sociodemographics, lifestyle, health, and well-being, as well as physical and psychosocial characteristics of the work environment (table 1).

The physicians had written instructions for recruitment and examination of patients including a checklist of necessary procedures. They were asked to keep a list of examined patients and record reasons for refusals.

Part- and full-time sick leave. In the intervention group (part-time sick leave), workload was reduced by restricting work time. The recommendation to reduce daily working time by about half was achieved in most cases (70\% of subjects). In some cases, when it was difficult to arrange work for half a day, the subjects worked 
Table 1. Characteristics of intervention and control group measured at baseline. [SD=standard deviation.]

\begin{tabular}{|c|c|c|c|c|c|c|}
\hline \multirow[t]{2}{*}{ Characteristic } & \multicolumn{3}{|c|}{$\begin{array}{l}\text { Control } \\
(\mathrm{N}=30)\end{array}$} & \multicolumn{3}{|c|}{$\begin{array}{l}\text { Intervention } \\
\quad(N=31)\end{array}$} \\
\hline & $\%$ & Mean & SD & $\%$ & Mean & SD \\
\hline Age & & 44.4 & 10.7 & & 44.2 & 10.1 \\
\hline Body mass index & & 27.1 & 5.3 & & 25.4 & 3.6 \\
\hline \multicolumn{7}{|l|}{$\begin{array}{l}\text { Lifting, carrying or push- } \\
\text { ing loads }>5 \mathrm{~kg} \text {, number of } \\
\text { times per working day }\end{array}$} \\
\hline $\begin{array}{l}\text { Median }\left(25^{\text {th }} \text { and } 75^{\text {th }}\right. \\
\text { percentile) }\end{array}$ & & 40 & $0-220$ & & 50 & $0-250$ \\
\hline $\begin{array}{l}\text { Awkward trunk postures, } \\
\text { often or constantly for } \geq 1 \\
\text { minute at a time }\end{array}$ & 30 & & & 39 & & \\
\hline \multicolumn{7}{|l|}{$\begin{array}{l}\text { Time since onset of symp- } \\
\text { toms (number elapsed days) }\end{array}$} \\
\hline $\begin{array}{l}\text { Median ( } 25^{\text {th }} \text { and } 75^{\text {th }} \\
\text { percentile) }\end{array}$ & & 48 & $7-234$ & & 42 & $8-87$ \\
\hline Pain intensity $(0-10)$ & & 6.3 & 1.5 & & 6.1 & 1.4 \\
\hline $\begin{array}{l}\text { Pain interference with } \\
\text { work }(0-10)\end{array}$ & & 6.6 & 1.4 & & 7.5 & 3.7 \\
\hline $\begin{array}{l}\text { Pain interference with } \\
\text { sleep }(0-10)\end{array}$ & & 3.7 & 2.7 & & 4.8 & 3.0 \\
\hline $\begin{array}{l}\text { Self-rated general health } \\
(0-10)\end{array}$ & & 6.8 & 1.6 & & 7.0 & 1.4 \\
\hline Standardized disability index & & 0 & 0.9 & & 0 & 1.0 \\
\hline $\begin{array}{l}\text { Perceived health-related } \\
\text { quality of life (5-15) }\end{array}$ & & 7.6 & 1.4 & & 7.4 & 1.0 \\
\hline Productivity loss $(0-100)$ & & 32.7 & 24 & & 32.4 & 25 \\
\hline Sleep disturbance & 40 & & & 37 & & \\
\hline Depression & 23 & & & 14 & & \\
\hline \multicolumn{7}{|l|}{ Effort-reward imbalance } \\
\hline Effort (1-5) & & 4.2 & 0.6 & & 4.2 & 0.6 \\
\hline Reward (1-5) & & 3.1 & 0.9 & & 3.0 & 0.8 \\
\hline Effort-reward ratio & & 1.5 & 0.6 & & 1.6 & 0.8 \\
\hline \multicolumn{7}{|l|}{ Organizational equity } \\
\hline Procedural justice (1-5) & & 2.3 & 1.0 & & 2.6 & 1.1 \\
\hline Relational justice (1-5) & & 2.0 & 1.0 & & 2.3 & 1.1 \\
\hline
\end{tabular}

shorter hours 3-4 days a week ( $30 \%$ of subjects). Also, if necessary, remaining work tasks were modified to control exacerbation of activity-related symptoms. The physician made recommendations to the patients on the duration of partial work disability, whether certain physical loads should be reduced, and whether any additional work modifications were necessary. The patients took the "fit note" to their supervisor the day following the consultation.

If the worker was unable to return to full duty after the initial part-time sick leave, part-time sick leave could be continued or changed to full-time sick leave based on medical assessment. Part-time sick leave could be extended for up to two months, if necessary. If the worker became unable to perform part-time work duties, full-time sick leave could be used instead based on medical assessment. In that case, the worker could not return to part-time sick leave.
Full-time absence was prescribed for the control group. In both groups, employees received their regular salary.

\section{Outcome measures}

Pain-related outcomes. Pain intensity on a scale from $0-10(0=$ no pain to $10=$ the worst possible pain $)$ and pain interference with work and sleep during the last 7 days (from $0=$ no interference at all to $10=$ the worst possible interference) were assessed at baseline, and weeks 1 , 3,8 , and 12 . Moreover, the region-specific disability instruments included a question on pain intensity, and this question served for the pain level at 52 weeks.

Region-specific disability. We used the Oswestry Disability Index to assess the disability level due to back pain (15), the Neck Disability Index to assess cervicalspine-related disabilities (16), the QuickDASH to assess the disabilities of the arm, shoulder, and hand (17), and the Comprehensive Osteoarthritis Test (COAT) (18) to assess the symptoms of the hip or knee. Disability was assessed at baseline and at 1, 3, 8, 12, and 52 weeks.

Self-rated general health. The respondents were asked to assess their self-rated health with a numerical scale from $0-10(0=$ worst possible health state to $10=$ best possible health state). General health was assessed at baseline and at weeks $1,3,8,12$, and 52 .

Perceived health-related quality of life. We assessed perceived health-related quality of life of the participants using the EQ-5D, a validated measure developed by the EuroQol (19). EQ-5D consists of five dimensions: (i) mobility, (ii) self-care, (iii) usual activities, (iv) pain/discomfort, and (v) anxiety/depression. Each dimension has three levels (no problems $=1$, some problems $=2$, extreme problems $=3$ ). In addition to using the score as a continuous variable (range 5-15), we also analyzed each dimension separately by dichotomizing it into "no problems" (level 1) versus "problems" (levels 2 and 3 ). We assessed perceived health-related quality of life at all time points.

Depression. Depression was assessed using two validated questions (20): (i) During the past month have you often been bothered by feeling down, depressed, or hopeless? and (ii) During the past month have you often been bothered by little interest or pleasure in doing things? We defined depression as a "yes" response to both questions. Depression was assessed at baseline and 12 and 52 weeks.

Sleep disturbance. We assessed sleep disturbances during the preceding four weeks by the Jenkins Sleep Problems Scale (21). It consists of 4 items on a 6-point rating scale $(1=$ never to $6=$ almost every night). The respon- 
dents were classified as having a sleep disturbance when they reported any of the 4 problems for most of the nights (5-7 nights per week) (22). Sleep disturbance was assessed at baseline and 12 and 52 weeks.

Productivity loss. Productivity loss at work was selfassessed using two questions recommended by Brouwer et al (23). The subjects were asked to consider the latest full or partial working day and compare it to their normal workday when answering the questions: (i) assess the amount of work you were able to perform, and (ii) assess the quality of your work. For both questions, the scale ranged from $0-10(0=$ very poor to $10=$ regular quantity or quality). In case the reported value was $<10$ for either question, the respondent was requested to indicate whether the reason was musculoskeletal, other health-related, or another problem. To estimate productivity loss, we used a formula "[1 - (quality/10) $\times($ quantity $/ 10)] \times 100 \%$ " modified from Hoeijenbos et al (24). Productivity loss was assessed at all time points.

\section{Covariates}

Individual characteristics. We inquired about age, height, weight, and the date of onset of current problem.

Physical workload factors. We inquired about the average number of times per working day of lifting, carrying, or pushing loads of 6-15 kg, 16-25 kg, or $>25$ $\mathrm{kg} \mathrm{(25),} \mathrm{and} \mathrm{awkward} \mathrm{trunk} \mathrm{postures} \mathrm{for} \geq 1$ minute at a time. We estimated the average number of times of lifting, carrying, or pushing loads $>5 \mathrm{~kg}$ per working day (26).

Psychosocial workload factors. Effort-reward imbalance was studied using a single question for effort and three questions for reward (27). Organizational equity was operationalized as procedural and relational justice (28).

\section{Randomization}

After symptom interview, physical examination, and assessment of the required length of sickness absence, the physicians randomized the employees. Block randomization (block size 4) was used in order to obtain equal number of intervention and control patients for each participating physician. Using a random number generator, a statistician at the Finnish Institute of Occupational Health performed the allocation. For each physician, a researcher prepared sequentially numbered sealed opaque envelopes, containing information on the allocated group. The envelopes were kept in a locked closet in each physician's office. Neither the employee nor the treating physicians were blinded for group allocation.

\section{Statistical analysis}

Region-specific disability was measured with different disability indices. In order to ensure that each measurement contributed equally to the final disability index, we standardized these variables using $\mathrm{Z}$-score. $\mathrm{Z}$-scores were calculated by subtracting the mean value (m) of the variable (x) from each subject's score and dividing the result by the standard deviation (SD) of the variable $[\mathrm{z}=(\mathrm{x}-\mathrm{m}) / \mathrm{SD}]$. A similar standardization process was performed for the pain levels at 52 weeks to make the different scales in the used disability indices comparable.

We used descriptive statistics to assess differences in the baseline characteristics between the intervention and control group. We used generalized estimating equation (GEE) with an exchangeable correlation structure to analyze differences between the groups in the repeated measures data (29). The link function was specified as "logit" for the dichotomized outcomes. We used robust variance estimator to compute standard errors. In addition to group allocation and follow-up time, we included body mass index (BMI, continuous), and time since the beginning of symptoms (number of elapsed days, continuous) as covariates in the models due to imbalance at baseline between the control and intervention group. We also adjusted for the baseline value of each outcome variable to control for the difference in the outcome measured at baseline between the intervention and control group. We were interested in how part-time sick leave influences recovery among employees with different intensity and duration of symptoms. Therefore, we performed subgroup analyses according to pain intensity $(<7$ versus $\geq 7)$ and time since the beginning of symptoms ( $\leq 6$ versus $>6$ weeks). Since our earlier results on an ergonomic intervention study in employees with upper-extremity disorders showed that only subjects with low level of productivity loss benefited from the intervention (30), we performed a subgroup analysis according to productivity loss $(\leq 30 \%,>30 \%$; based on the median). We used Stata, version 10, (StataCorp, College Station, TX, USA) for the analyses.

\section{Results}

\section{Baseline characteristics}

All study subjects, except two (one in each group), were female. Subjects in the control group had higher BMI and region-specific disability at baseline than those in the intervention group. They reported depression more frequently and a longer time since beginning of their 
symptoms, but a lower level of pain interference with work or sleep compared with the intervention group. The groups were fairly similar with regard to work-related physical and psychosocial factors. There were no major differences between the groups in the other characteristics (table 1).

\section{Pain-related outcomes}

Pain intensity and interference with work and sleep decreased in both the control and intervention group during the first 8 weeks and stabilized thereafter. For instance, pain intensity after 1 week was 5.3 in the control and 5.4 in the intervention group, after 8 weeks it was 3.8 and 3.4, respectively, and after 12 weeks 4.5 and 3.3, respectively. During the follow-up period, there were no differences between the groups in either pain intensity or interference with work or sleep (table 2).

\section{Region-specific disability}

Region-specific disability did not differ between the intervention and control group (table 2).

\section{Self-rated general health and health-related quality of life}

The intervention group reported better self-rated general health and higher health-related quality of life (EuroQol) than the control group (table 2). After adjustment for follow-up time, BMI, time since beginning of symptoms and the baseline measure of the variable, the difference between the two groups remained statistically significant for health-related quality of life $(\mathrm{P}=0.02)$ and marginally significant for self-rated general health $(\mathrm{P}=0.07)$. The differences in health-related quality of life $(\mathrm{P}=0.008)$ and general health $(\mathrm{P}=0.06)$ increased after further adjustment for pain interference with work and sleep at baseline.

Of the dimensions of health-related quality of life, improvement was higher in the intervention than the control group in usual activities [adjusted odds ratio (OR) $0.47,95 \%$ confidence interval $(95 \% \mathrm{CI}) 0.22-0.98]$.

\section{Other outcomes}

The groups did not differ with regard to productivity loss, depression, or sleep disturbance.

\section{Subgroup analysis}

The effect of the intervention did not differ between subjects with low $(<7)$ and high $(\geq 7)$ pain intensity at baseline with regard to pain-related outcomes, regionspecific disability, general health, health-related quality of life, or productivity loss. Among those with low pain intensity at baseline, sleep problems were less frequent in the intervention than the control group (adjusted OR $0.1,95 \%$ CI $0.0-0.3$ ).

The intervention was more effective among subjects whose problems began occurring $<6$ weeks before the baseline. In this subgroup, the intervention group had statistically significantly better general health $(\mathrm{P}=0.05)$ and higher health-related quality of life $(\mathrm{P}=0.03)$ than the control group (table 3 ). Of the dimensions of healthrelated quality of life, the intervention had effects on usual activities (adjusted OR 0.3, 95\% CI 0.1-0.6), and anxiety/depression (OR 0.1, 95\% CI 0.0-0.8). Moreover, the intervention group reported less sleep problems than the control group (OR $0.1,95 \%$ CI $0.0-0.4$ ).

Table 2. Effects of intervention on health-related outcomes [regression coefficients (log scale), 95\% confidence intervals (95\% Cl) and P-values]. [Obs=number of repeated observations; $S D=$ standard deviation.]

\begin{tabular}{|c|c|c|c|c|c|c|c|c|c|c|c|c|}
\hline \multirow[t]{2}{*}{ Characteristic } & \multicolumn{3}{|c|}{ Control } & \multicolumn{3}{|c|}{ Intervention } & \multicolumn{3}{|c|}{ Crude } & \multicolumn{3}{|c|}{ Adjusted a } \\
\hline & Obs & Mean & $\overline{S D}$ & Obs & Mean & SD & Coefficient ${ }^{b}$ & $95 \% \mathrm{Cl}$ & $\begin{array}{c}\mathrm{P}- \\
\text { value }\end{array}$ & Coefficient ${ }^{b}$ & $95 \% \mathrm{Cl}$ & $\begin{array}{c}\mathrm{P}- \\
\text { value }\end{array}$ \\
\hline Pain intensity ( $\leq 3$ months) & 148 & 4.9 & 2.5 & 147 & 4.5 & 2.8 & -0.3 & $-1.2-0.6$ & 0.51 & -0.4 & $-1.3-0.4$ & 0.31 \\
\hline $\begin{array}{l}\text { Pain interference with work } \\
\text { ( } \leq 3 \text { months) }\end{array}$ & 99 & 4.7 & 2.8 & 123 & 4.2 & 2.9 & -0.6 & $-1.6-0.4$ & 0.23 & -0.7 & $-1.6-0.3$ & 0.15 \\
\hline $\begin{array}{l}\text { Pain interference with sleep } \\
\text { ( } \leq 3 \text { months })\end{array}$ & 148 & 3.2 & 2.8 & 148 & 3.3 & 3.0 & 0.1 & $-1.0-1.1$ & 0.91 & -0.12 & $-0.9-0.7$ & 0.77 \\
\hline Pain at 1 year, standardized & 27 & 0.2 & 1.0 & 28 & -0.2 & 0.9 & -0.4 & $-0.9-0.1$ & 0.10 & -0.2 & $-0.7-0.4$ & 0.48 \\
\hline $\begin{array}{l}\text { Standardized disability index } \\
\text { ( } \leq 12 \text { months) }\end{array}$ & 173 & 0.1 & 0.9 & 176 & -0.1 & 1.0 & -0.1 & $-0.5-0.2$ & 0.42 & -0.1 & $-0.4-0.2$ & 0.54 \\
\hline $\begin{array}{l}\text { Self-rated general health } \\
\text { ( } \leq 12 \text { months })\end{array}$ & 176 & 7.0 & 1.9 & 180 & 7.6 & 1.6 & 0.6 & $0.0-1.2$ & 0.04 & 0.5 & $-0.0-1.0$ & 0.07 \\
\hline $\begin{array}{l}\text { Perceived health-related quality } \\
\text { of life ( } \leq 12 \text { months) }\end{array}$ & 175 & 7.2 & 1.6 & 177 & 6.6 & 1.4 & -0.6 & $-1.2--0.1$ & 0.03 & -0.5 & $-0.9--0.1$ & 0.02 \\
\hline Productivity loss ( $\leq 12$ months) & 131 & 23.9 & 24.2 & 149 & 22.6 & 26.7 & -0.6 & $-9.1-7.9$ & 0.88 & 2.3 & $-4.8-9.5$ & 0.52 \\
\hline
\end{tabular}

a Adjusted for body mass index, follow-up time, time since beginning of symptoms (number of elapsed days) and the baseline measure of the outcome.

${ }^{b}$ Negative coefficients reflect an effect in favour of the intervention group; except for "self-rated general health". 
The intervention was effective among subjects with $\leq 30 \%$ productivity loss at baseline, but not those with reduced productivity of $>30 \%$ (table 3 ). The effect was found for pain intensity and interference with work, region-specific disability, self-rated general health, and health-related quality of life.

Among those with $\leq 30 \%$ productivity loss at baseline, the intervention group reported lower productivity loss than the control group throughout the follow-up period. In contrast, among those with reduced productivity of $>30 \%$, the intervention group reported higher productivity loss than the control group.

\section{Discussion}

The current study suggests that, compared to full-time absence, part-time sick leave may improve self-rated general health and health-related quality of life in the early stage of work disability due to MSD. Furthermore, there was no indication of part-time sick leave exacerbating pain intensity, pain interference with work or sleep, or functional disability. The positive health effect was seen, although workers in the intervention group had higher work participation throughout the follow-up and were more exposed to physical workloads than the control group (11). Part-time sick leave may not be more effective than full-time sick leave among individuals with longer lasting MSD or substantially reduced productivity.

MSD impair quality of life (31). The current study suggests that part-time work improves quality of life and also perceived health. An earlier study found that patients on part-time sick leave believe that part-time work is good for their health (32).

The intervention in our study has two elements: (i) by halving work time, the intervention achieved a considerable reduction in workload and (ii) it offered patients the possibility to participate in work. The information from our subgroup analyses can be used for the selection of subjects who would benefit more from work modification. Our results indicated that those with symptoms of short duration and only slightly reduced productivity benefited more from the intervention, while severity of symptoms did not seem to play a role. In this study, we used high pain intensity as an exclusion criterion. The current results suggest that chronicity of symptoms and level of productivity loss could serve as more valid selection criteria.

The intervention in this study was restricted to the reduction of work time, sometimes combined with slight work modifications. In case of more chronic symptoms and higher productivity loss, substantial work modifications and more individually focused measures would likely be needed, such as cognitive behavioral approaches and the development of problem solving strategies (33).

Table 3. Effects of intervention on health-related outcomes [regression coefficients (log scale), 95\% confidence intervals (95\% Cl) and P-values] according to time since beginning of symptoms (number of elapsed days) and productivity loss at baseline. [Obs $(\mathrm{C} / \mathrm{l})=$ number of repeated observations (control / intervention)]

\begin{tabular}{|c|c|c|c|c|c|c|c|c|c|c|c|c|c|c|c|}
\hline \multirow[t]{3}{*}{ Outcome } & \multicolumn{8}{|c|}{ Time since beginning of symptoms } & \multicolumn{7}{|c|}{ Productivity loss } \\
\hline & \multicolumn{4}{|c|}{$\leq 6$ weeks } & \multicolumn{4}{|c|}{$>6$ weeks } & \multicolumn{4}{|c|}{$\leq 30 \%$} & \multicolumn{3}{|c|}{$>30 \%$} \\
\hline & $\begin{array}{l}\text { Obs } \\
(\mathrm{C} / \mathrm{l})\end{array}$ & $\begin{array}{c}\text { Co- } \\
\text { efficient }{ }^{a, b}\end{array}$ & $95 \% \mathrm{Cl}$ & $\begin{array}{c}\text { P- } \\
\text { value }\end{array}$ & $\begin{array}{l}\text { Obs } \\
(\mathrm{C} / \mathrm{l})\end{array}$ & $\begin{array}{c}\text { Co- } \\
\text { efficient } a, b\end{array}$ & $95 \% \mathrm{Cl}$ & $\begin{array}{c}P- \\
\text { value }\end{array}$ & $\begin{array}{l}\text { Obs } \\
(\mathrm{C} / \mathrm{l})\end{array}$ & $\begin{array}{c}\text { Co- } \\
\text { efficient }{ }^{a, b}\end{array}$ & $95 \% \mathrm{Cl}$ & $\begin{array}{c}P- \\
\text { value }\end{array}$ & $\begin{array}{l}\text { Obs } \\
(\mathrm{C} / \mathrm{l})\end{array}$ & $\begin{array}{c}\text { Co- } \\
\text { efficient a,b }\end{array}$ & b5\% Cl $\begin{array}{c}\mathrm{P}- \\
\text { value }\end{array}$ \\
\hline $\begin{array}{l}\text { Pain intensity } \\
\text { ( } \leq 3 \text { months) }\end{array}$ & $65 / 76$ & -0.8 & $-2.0-0.4$ & 0.18 & $78 / 71$ & 0.2 & $-0.9-1.3$ & 0.71 & $74 / 80$ & -1.1 & $-2.2-0.1$ & 0.07 & $74 / 67$ & 0.2 & $-0.9-1.30 .77$ \\
\hline $\begin{array}{l}\text { Pain interference } \\
\text { with work ( } \leq 3 \\
\text { months) }\end{array}$ & $44 / 69$ & -0.9 & $-2.1-0.3$ & 0.14 & $53 / 54$ & -0.3 & $-1.4-0.9$ & 0.65 & $44 / 67$ & -1.4 & $-2.7--0.2$ & 0.02 & $55 / 56$ & 0.0 & $-1.3-1.40 .95$ \\
\hline $\begin{array}{l}\text { Pain interference } \\
\text { with sleep ( } \leq 3 \\
\text { months) }\end{array}$ & $64 / 75$ & -0.4 & $-1.5-0.6$ & 0.41 & $79 / 73$ & -0.1 & $-1.0-0.9$ & 0.90 & $73 / 81$ & -0.7 & $-1.7-0.3$ & 0.18 & $75 / 67$ & 0.5 & $-0.5-1.60 .32$ \\
\hline $\begin{array}{l}\text { Standardized } \\
\text { disability index } \\
\text { ( } \leq 12 \text { months) }\end{array}$ & $75 / 90$ & -0.2 & $-0.6-0.1$ & 0.15 & $93 / 86$ & -0.0 & $-0.5-0.4$ & 0.88 & $87 / 97$ & -0.4 & $-0.8-0.0$ & 0.05 & $86 / 79$ & 0.1 & $-0.3-0.50 .58$ \\
\hline $\begin{array}{l}\text { Self-rated } \\
\text { general health } \\
\text { ( } \leq 12 \text { months) }\end{array}$ & $77 / 91$ & 0.8 & $0.0-1.6$ & 0.05 & $93 / 89$ & 0.1 & $-0.4-0.5$ & 0.80 & $87 / 100$ & 1.0 & $0.1-1.9$ & 0.02 & $89 / 80$ & 0.0 & $-0.4-0.40 .97$ \\
\hline $\begin{array}{l}\text { Perceived health- } \\
\text { related quality of } \\
\text { life ( } \leq 12 \text { months) }\end{array}$ & $77 / 88$ & -0.6 & $-1.2--0.1$ & 0.03 & $92 / 89$ & -0.3 & $-0.8-0.2$ & 0.19 & $86 / 99$ & -0.6 & $-1.0--0.1$ & 0.01 & $89 / 78$ & $\begin{array}{ll}3 & -0.2\end{array}$ & $-0.9-0.40 .48$ \\
\hline $\begin{array}{l}\text { Productivity loss } \\
\text { ( } \leq 12 \text { months) }\end{array}$ & $57 / 83$ & 2.5 & $-10.7-15.6$ & 0.71 & $71 / 66$ & 2.3 & $-4.7-9.3$ & 0.52 & $62 / 84$ & -7.8 & $-14.7--0.9$ & 0.02 & $69 / 65$ & $5 \quad 12.0$ & $0.5-23.60 .04$ \\
\hline
\end{tabular}

a Adjusted for body mass index, follow-up time, time since beginning of symptoms (number of elapsed days) and the baseline measure of the outcome.

'Negative coefficients reflect an effect in favour of the intervention group; except for "self-rated general health". 
Previous studies $(3,4)$ indicate that staying active instead of bed rest improves recovery from MSD and related disability. The current study supports this advice for earlier stages of work disability due to MSD. Moreover, in line with our earlier study (30), this study suggests that ergonomic work modifications are effective only among employees whose symptoms do not significantly impair their perceived productivity at work. The reduction of working hours is an opportunity for employees to remain active at work (34). Furthermore, partial RTW often precedes full RTW (35).

These results emphasize the fact that already the first encounter between the employee with recent MSD and the physician is important in relation to the risk of sickness absence in the future. It might be that, at this stage, the choice of treatment is not considered very important because most cases will recover soon anyway. Our study shows, however, that active input from the physician's side is needed already at this stage if future work disability is to be avoided.

Early interventions are nowadays strongly encouraged in many countries. In the UK, instead of the "sick note", the "fit note" is being promoted as a means to support the use of active alternatives instead of traditional sick leave. In Norway, the same is made possible during the employer period (ie, the first 16 days), and in Denmark the physicians must issue "a report of possibilities" for employees after two weeks of sick leave. Physicians in Sweden can use a graded scale from $25-100 \%$ when assessing disability, and in Finland part-time sick leave can be recommended after two weeks of work disability. The present study supports the effectiveness of these active approaches in the management of MSD.

The present study has some weaknesses. The trial had a low power to detect the true effect of the intervention. However, even with this small sample, the effect of the intervention reached statistical significance for some health-related outcomes. Neither the patients nor the physicians were blinded for the intervention. In this type of intervention - in which the patient him/herself is an actor in the process - blinding is impossible. Moreover, the physicians had made decisions regarding the length of sick leave and medication before randomization. We used self-rated health to assess perceived current health status. This is a subjective measure, but it seems to be a useful tool for predicting future health outcomes $(36,37)$.

Subjects were asked to report their productivity during the last full- or part-time work day. Since the control group was on sick leave more than the intervention group, the last work day may have been more distant in time in the control than the intervention group.

Altogether, our findings suggest that part-time sick leave - in addition to reducing sickness absenteeism may have positive effects on self-rated general health and health-related quality of life and may not exacerbate pain-related symptoms and functional disability in the early stage of work disability due to MSD.

\section{Acknowledgements}

We thank Heidi Furu, Tuomo Pienimäki, Martti Rechardt, and Katja Ryynänen for examining patients, Merja Joutsenlahti and Eeva Hallikainen for patient information and other arrangements during the study, Ritva Ketola, Martta Ranta, Hilkka Riihimäki, and Tuija Toikka for participating at the earlier stages of the study, and participating enterprises and their occupational health personnel who referred patients to the study.

The study was supported by the Work Environment Fund (grant number 106304), the Ministry of Social Affairs and Health, and the Social Insurance Institution of Finland. The authors were independent of the funders and the funders had no role in the project. The trial is registered under Current Controlled Trials ISRCTN30911719.

The authors declare that they have no competing interests.

\section{References}

1. Shiri R, Varonen H, Heliövaara M, Viikari-Juntura E. Hand dominance in upper extremity musculoskeletal disorders. J Rheumatol. 2007;34(5):1076-82.

2. Roux $\mathrm{CH}$, Guillemin F, Boini S, Longuetaud F, Arnault $\mathrm{N}$, Hercberg S, et al. Impact of musculoskeletal disorders on quality of life: an inception cohort study. Ann Rheum Dis. 2005;64(4):606-11. http://dx.doi.org/10.1136/ ard.2004.020784.

3. Zebis MK, Andersen LL, Pedersen MT, Mortensen P, Andersen CH, Pedersen MM, et al. Implementation of neck/ shoulder exercises for pain relief among industrial workers: A randomized controlled trial. BMC Musculoskelet Disord. 2011;12:205. http://dx.doi.org/10.1186/1471-2474-12-205.

4. Krismer M, van Tulder M. Strategies for prevention and management of musculoskeletal conditions. Low back pain (non-specific). Best Pract Res Clin Rheumatol. 2007;21(1):7791. http://dx.doi.org/10.1016/j.berh.2006.08.004.

5. Waddell G, Burton AK. Is work good for your health and wellbeing? London: TSO (The Stationery Office); 2006.

6. Kivimäki M, Forma P, Wikstrom J, Halmeenmäki T, Pentti J, Elovainio M, et al. Sickness absence as a risk marker of future disability pension: the 10-town study. J Epidemiol Community Health. 2004;58(8):710-1. http://dx.doi.org/10.1136/ jech.2003.015842.

7. Järvholm B. How should methods for return to work be 
evaluated? Scand J Work Environ Health. 2012;38(2):89-91. http://dx.doi:10.5271/sjweh.3277

8. Joyce K, Pabayo R, Critchley JA, Bambra C. Flexible working conditions and their effects on employee health and wellbeing. Cochrane Database Syst Rev. (2):CD008009.

9. Hogelund J, Holm A, McIntosh J. Does graded return-to-work improve sick-listed workers' chance of returning to regular working hours? J Health Econ. 2010;29(1):158-69. http:// dx.doi.org/10.1016/j.jhealeco.2009.11.009.

10. Kausto J, Virta L, Luukkonen R, Viikari-Juntura E. Associations between partial sickness benefit and disability pensions: initial findings of a Finnish nationwide register study. BMC Public Health. 2010;10:361. http://dx.doi. org/10.1186/1471-2458-10-361.

11. Viikari-Juntura E, Kausto J, Shiri R, Kaila-Kangas L, Takala EP, Karppinen J, et al. Return to work after early part-time sick leave due to musculoskeletal disorders: a randomized controlled trial. Scand J Work Environ Health. 2011 Oct 27. [Epub ahead of print]. http://dx.doi.org/10.5271/sjweh.3258.

12. Kausto J, Miranda H, Martimo KP, Viikari-Juntura E. Partial sick leave--review of its use, effects and feasibility in the Nordic countries. Scand J Work Environ Health. 2008;34(4):239-49. http://dx.doi.org/10.5271/sjweh.1266.

13. Viikari-Juntura E, Takala EP, Riihimäki H, Malmivaara A, Martikainen R, Jäppinen P. Standardized physical examination protocol for low back disorders: feasibility of use and validity of symptoms and signs. J Clin Epidemiol. 1998;51(3):245-55. http://dx.doi.org/10.1016/S0895-4356(97)00266-7.

14. Viikari-Juntura E, Takala E, Riihimäki H, Martikainen R, Jappinen P. Predictive validity of symptoms and signs in the neck and shoulders. J Clin Epidemiol. 2000;53(8):800-8. http://dx.doi.org/10.1016/S0895-4356(00)00197-9.

15. Fairbank JC, Pynsent PB. The Oswestry Disability Index. Spine (Phila Pa 1976). 2000;25(22):2940-52; discussion 2952.

16. Viikari-Juntura E, Takala EP, Alaranta H. Neck and shoulder pain and disability. Evaluation by repetitive gripping test. Scand J Rehabil Med. 1988;20(4):167-73.

17. Beaton DE, Wright JG, Katz JN. Development of the QuickDASH: comparison of three item-reduction approaches. J Bone Joint Surg Am. 2005;87(5):1038-46. http://dx.doi. org/10.2106/JBJS.D.02060.

18. Brooks LO, Rolfe MI, Cheras PA, Myers SP. The comprehensive osteoarthritis test: a simple index for measurement of treatment effects in clinical trials. J Rheumatol. 2004;31(6):1180-6.

19. EuroQol Group. EuroQol--a new facility for the measurement of health-related quality of life. Health Policy. 1990;16(3):199208. http://dx.doi.org/10.1016/0168-8510(90)90421-9.

20. Arroll B, Khin N, Kerse N. Screening for depression in primary care with two verbally asked questions: cross sectional study. BMJ. 2003;327(7424):1144-6. http://dx.doi.org/10.1136/ bmj.327.7424.1144.

21. Jenkins CD, Stanton BA, Niemcryk SJ, Rose RM. A scale for the estimation of sleep problems in clinical research. J Clin Epidemiol. 1988;41(4):313-21. http://dx.doi. org/10.1016/0895-4356(88)90138-2.
22. Salminen $S$, Oksanen T, Vahtera J, Sallinen M, Härmä M, Salo P, et al. Sleep disturbances as a predictor of occupational injuries among public sector workers. J Sleep Res. 2010;19(1 Pt 2):207-13. http://dx.doi.org/10.1111/j.13652869.2009.00780.x.

23. Brouwer WB, Koopmanschap MA, Rutten FF. Productivity losses without absence: measurement validation and empirical evidence. Health Policy. 1999;48(1):13-27. http://dx.doi. org/10.1016/S0168-8510(99)00028-7.

24. Hoeijenbos M, Bekkering T, Lamers L, Hendriks E, van Tulder M, Koopmanschap M. Cost-effectiveness of an active implementation strategy for the Dutch physiotherapy guideline for low back pain. Health Policy. 2005;75(1):85-98. http:// dx.doi.org/10.1016/j.healthpol.2005.02.008.

25. Viikari-Juntura E, Rauas S, Martikainen R, Kuosma E, Riihimäki H, Takala EP, et al. Validity of self-reported physical work load in epidemiologic studies on musculoskeletal disorders. Scand J Work Environ Health. 1996;22(4):251-9. http://dx.doi.org/10.5271/sjweh.139.

26. Washington State Dept of Labor \& Industries. Public Law: WAC 296-62-051, Ergonomics (Repealed by ballot initiative12/4/03). (accessed 11 October 2011) 2003. Available from: http://www. lni.wa.gov/WISHA/Rules/generaloccupationalhealth/PDFs/ ErgoRulewithAppendices.pdf

27. Taris TW, Kalimo R, Schaufeli WB. Inequity at work: its measurements and association with worker health. Work \& Stress. 2002;16:287-301. http://dx.doi.org/10.1080/026783 7021000054500

28. Moorman RH. Relationship between organizational justice and organizational citizenship behaviors: Do fairness perceptions influence employee citizenship? J Appl Psychol. 1991;76:84555. http://dx.doi.org/10.1037/0021-9010.76.6.845.

29. Hanley JA, Negassa A, Edwardes MD, Forrester JE. Statistical analysis of correlated data using generalized estimating equations: an orientation. Am J Epidemiol. 2003;157(4):364 75. http://dx.doi.org/10.1093/aje/kwf215.

30. Martimo KP, Shiri R, Miranda H, Ketola R, Varonen H, Viikari-Juntura E. Effectiveness of an ergonomic intervention on the productivity of workers with upper-extremity disorders-a randomized controlled trial. Scand J Work Environ Health. 2010;36(1):25-33. http://dx.doi.org/10.5271/sjweh.2880.

31. Peilot B, Andrell P, Mannerkorpi K, Mannheimer C. Quality of life assessed with Short Form 36 - a comparison between two populations with long-term musculoskeletal pain disorders. Disabil Rehabil. 2010;32(23):1903-9. http://dx.doi. org/10.3109/09638281003734383.

32. Sieurin L, Josephson M, Vingard E. Positive and negative consequences of sick leave for the individual, with special focus on part-time sick leave. Scand J Public Health. 2009;37(1):50 6. http://dx.doi.org/10.1177/1403494808097171.

33. Lambeek LC, Anema JR, van Royen BJ, Buijs PC, Wuisman PI, van Tulder MW, et al. Multidisciplinary outpatient care program for patients with chronic low back pain: design of a randomized controlled trial and cost-effectiveness study [ISRCTN28478651]. BMC Public Health. 2007;7:254. http:// dx.doi.org/10.1186/1471-2458-7-254. 
34. Henriksson CM, Liedberg GM, Gerdle B. Women with fibromyalgia: work and rehabilitation. Disabil Rehabil. 2005;27(12):685-94. http://dx.doi. org/10.1080/09638280400009089.

35. Josephson M, Heijbel B, Voss M, Alfredsson L, Vingard E. Influence of self-reported work conditions and health on full, partial and no return to work after long-term sickness absence. Scand J Work Environ Health. 2008;34(6):430-7. http:// dx.doi.org/10.5271/sjweh.1289.
36. Hasson D, Arnetz BB, Theorell T, Anderberg UM. Predictors of self-rated health: a 12-month prospective study of IT and media workers. Popul Health Metr. 2006;4:8. http://dx.doi. org/10.1186/1478-7954-4-8.

37. Lima-Costa MF, Cesar CC, Chor D, Proietti FA. Self-rated health compared with objectively measured health status as a tool for mortality risk screening in older adults: 10-year follow-up of the Bambui Cohort Study of Aging. Am J Epidemiol. 2011;175(3):228-35. http://dx.doi.org/10.1093/ aje/kwr290.

Received for publication: 27 January 2012 